\title{
PERAN GURU DALAM MENGHADAPI BULLY TERHADAP ANAK GAGAP DARI TEMAN SEBAYA
}

\section{THE ROLE OF THE TEACHER IN FACING BULLY TOWARD STAFFING CHILDREN FROM PEERS}

\author{
Oleh : \\ Yubaedi Siron ${ }^{1}$ \\ Mardhiah $^{2}$ \\ Isti Fajriah Nurrahma ${ }^{3}$ \\ Anbar Salsabila ${ }^{4}$
}

Submitted:

$04-07$ - 2020

Revision:

$10-02-2021$

Accepted:

$18-02-2021$

\section{ABSTRACT}

Bullying is an action that can threaten others. Bullying occurs at the Early Childhood Education (ECE) level, which peers can do. This study aims to determine the role of ECE teachers to encounter bullying in stuttering children by peers. The study uses a phenomenological approach. Data collection is done by structured interviews. Participants were determined through purposive sampling, involving four participants who work as a teacher at the ECE center and experienced bullying of stuttering children by peers. The results revealed that the role of ECE teachers in dealing with bullying of stuttering children by peers include monitoring children's activities at school, managing classrooms, being a 'listener' of children's stories, being a good example, giving advice, giving rewards, consulting to family psychologists and provide education about special need children.

Keywords: Bullying, stuttering children, peers, teacher's role

\begin{abstract}
ABSTRAK
Bullying merupakan tindakan yang dapat membahayakan seseorang. Bullying dapat terjadi pada jenjang Pendidikan Anak Usia Dini (PAUD) yang dapat dilakukan oleh teman sebaya. Penelitian ini bertujuan untuk mengetahui peran guru PAUD dalam menghadapi bullying pada anak gagap oleh teman sebaya. Penelitian menggunakan pendekatan fenomenologis. Pengumpulan data dilakukan dengan wawancara terstruktur. Partisipan ditentukan melalui purposive sampling, dengan melibatkan empat patisipan yang berprofesi sebagai guru pada jenjang PAUD dan memiliki pengalaman dalam menangani kasus bullying terhadap anak gagap yang dilakukan oleh teman sebaya. Hasil penelitian mengungkapkan bahwa peran guru PAUD dalam menghadapi bullying anak gagap dari teman sebaya diantaranya yaitu memantau aktivitas anak di sekolah, melakukan pengelolaan kelas, menjadi 'pendengar' segala cerita anak, menjadi teladan yang baik, pemberi nasihat, melakukan pemberian reward, konsultasi psikolog keluarga, dan mengadakan edukasi tentang anak berkebutuhan khusus.
\end{abstract}

Kata kunci: Bullying, anak gagap, teman sebaya, peran guru

\footnotetext{
${ }^{1}$ Yubaedi Siron, Universitas Islam Negeri Syarif Hidayatullah Jakarta, yubaedi.siron@uinjkt.ac.id

${ }^{2}$ Mardhiah, Universitas Islam Negeri Syarif Hidayatullah Jakarta, mardhiah.dhiah17@mhs.uinjkt.ac.id

${ }^{3}$ Isti Fajriah Nurrahma, Universitas Islam Negeri Syarif Hidayatullah Jakarta,

isti.nurrahma17@mhs.uinjkt.ac.id

${ }^{4}$ Anbar Salsabila, Universitas Islam Negeri Syarif Hidayatullah Jakarta,

anbar.salsabila17@mhs.uinjkt.ac.id
} 


\section{PENDAHULUAN}

Komisi Perlindungan Anak Indonesia (KPAI) menyatakan dari tahun 2011 sampai Agustus 2014 tercatat 1.480 kasus bullying yang terjadi di sekolah (KPAI, 2014). Bullying merupakan tindakan memperlihatkan kekuasaan dengan cara menyakiti seseorang atau sekelompok orang, baik secara verbal maupun non verbal, sehingga menyebabkan korban menjadi depresi, trauma, merasa teraniaya, dan lemah (Nusantara, 2008). Bullying seringkali melibatkan beberapa anak, dilakukan berulang-ulang untuk memenuhi kebutuhan anak yang berkuasa di lingkungan sosialnya, serta menjadi berbahaya bagi anak yang tidak mampu menghadapinya (Robinson \& Maines, 2008).

Anak yang memiliki keterbatasan (kekurangan) pada dirinya, seperti gagap, menjadi salah satu ciri-ciri korban yang menjadi sasaran tindakan bullying (Nusantara, 2008; H. Sari \& Gökdağ, 2017; Siron, Khotimah, \& Sholeha, 2020; Yoshikazu et al., 2019a). Anak gagap bisa mendapat tindakan bullying dari teman sebayanya dikarenakan cara berbicaranya yang tidak sama seperti anak-anak pada umumnya (Cook \& Howell, 2014; H. Sari \& Gökdağ, 2017; Siron et al., 2020). Gagap sebagai gangguan kelancaran berbicara dimana cara berbicara seseorang menjadi terbata-bata, tiba-tiba berhenti, atau mengulang-ulang penyebutan kata ketika hendak menyampaikan kalimat (Fradelos, 2015; Indah, 2017; Yoshikazu et al., 2019a). Gagap adalah kondisi dimana aliran ucapan menjadi terjeda serta adanya pengulangan dan perpanjangan kata (Alfatihaturrohmah, Mayangsari, \& Karim, 2018; H. Sari \& Gökdăg, 2017; Yoshikazu et al., 2019b).

Perilaku bullying bisa terjadi dimana saja(Cook \& Howell, 2014; Goryl, NeilsenHewett, \& Sweller, 2013; Humphrey \& Crisp, 2008; Small, Neilsen-hewett, \& Sweller, 2013), termasuk di sekolah pada jenjang Pendidikan Anak Usia Dini (PAUD). Bullying yang terjadi pada anak usia dini dapat dilakukan oleh teman sebaya (Putri, 2017; Siron et al., 2020). Dengan demikian, dibutuhkan peran guru untuk dapat mengenali, mengidentifikasi, dan menangani anak (Garvis, Pendergast, \& Kanasa, 2013; Rozie, Haryani, \& Safitri, 2019; Siron, 2020; Souto-Manning, 2013). Guru seharusnya menjadi orang pertama dalam menangani kasus bullying sebab interaksi antara anak didik dengan guru terbilang lebih lama dibandingkan dengan staf lainnya di sekolah(H. Kim, 2009; King-Sears \& Strogilos, 2020; Wilson, Marks Woolfson, \& Durkin, 2020). Peran guru cukup besar dalam memberi pengetahuan tentang bullying dan mengimplementasikan kebijakan yang tegas serta konsisten terhadap perilaku bullying (Rahmawati, Tairas, \& Nawangsari, 2018; Tanod, 2018). Di sisi lain, guru mempunyai peran untuk memunculkan dukungan yang positif terhadap pelaku maupun korban bullying (A. K. Sari, Neviyarni, Karneli, \& Netrawati, 2020; Siswati \& Widayanti, 2009).

Penelitian terkait peran guru dalam menghadapi bullying pada peserta didik telah banyak diteliti, di antaranya yaitu penelitian oleh Mandiri (2017) dengan judul Peran Guru dalam Mengatasi Perilaku Bullying, pada Siswa Kelas Atas di SD Muhammadiyah 6 Surakarta; Alfalah (2017) dengan judul Peran Guru dalam Mengatasi Bullying di MI Negeri Trobayan Kalijambe Sragen; Ismail (2019) dengan judul Pentingnya Peran Guru Kelas dalam Mengatasi Perilaku Bullying Siswa di Sekolah; Arumsari dan Setyawan (2019) dengan judul Peran Guru dalam Pencegahan Bullying di PAUD; Choirudin (2019) dengan judul Peran Guru dalam Menanggulangi Perilaku Bullying pada Siswa Madrasah Ibtidaiyah Maarif Maesan; Lathifah (2019) dengan judul Peran Guru dalam Menangani Perilaku Tindakan Bullying Siswa Kelas V di MIN Baki Sukoharjo. 


\section{Psycho Idea, Volume 19 Nomer 01 Tahun 2021}

Belum banyak penelitian yang mengkaji tentang bagaimana peran guru dalam menghadapi bullying terhadap anak gagap yang dilakukan oleh teman sebaya di jenjang PAUD. Tujuan penelitian ini untuk mendeskripsikan peran guru dalam menghadapi anak gagap (stuttering) yang mengalami bullying oleh temannya di PAUD. Untuk itu, penelitian ini berkontribusi untuk menyajikan peran guru dalam menghadapi bullying terhadap anak gagap dari teman sebaya pada jenjang PAUD.

\section{METODE PENELITIAN}

Penelitian ini menggunakan pendekatan kualitatif dengan metode fenomenologis. Penelitian ini bertujuan untuk mengungkap bagaimana peran guru dalam menghadapi tindakan bullying anak gagap dari teman sebaya di PAUD. Pengumpulan data dalam penelitian ini menggunakan wawancara terstruktur. Instrumen wawancara disusun dan dikonsultasikan dengan pakar sebelum digunakan untuk mengambil data. Waktu wawancara disesuaikan antara waktu yang dimiliki narasumber dengan waktu luang yang dimiliki peneliti.

Partisipan dalam penelitian ini ditentukan melalui purposive sampling dengan melibatkan empat narasumber sesuai dengan kriteria yang telah ditentukan, yaitu narasumber berprofesi sebagai guru pada jenjang PAUD dan memiliki pengalaman dalam menghadapi (menangani) kasus bullying terhadap anak gagap yang dilakukan oleh teman sebaya.

Tabel 1.

Karakteristik Narasumber

\begin{tabular}{lllll}
\hline Karakteristik Pembeda & N1 & \multicolumn{1}{c}{ N2 } & N3 & \multicolumn{1}{c}{ N4 } \\
\hline Inisial & JF & HG & MY & RL \\
\hline Jenis Kelamin & Perempuan & Perempuan & Perempuan & Perempuan \\
\hline Pendidikan Terakhir & S1 PAUD & S2 & SMA & SMK
\end{tabular}

Keterangan:

KP: Karakteristik Pembeda

N1: Partisipan 1

N2: Partisipan 2

N3: Partisipan 3

N4: Partisipan 4

Wawancara dilakukan dengan jarak jauh secara daring setelah keempat narasumber menyetujui dan berkenan untuk diwawancarai mengenai bagaimana peran guru PAUD dalam menghadapi tindakan bullying anak gagap dari teman sebaya. Informan menyetujui form informan consent sebelum wawancara dilakukan. Pedoman wawancara untuk guru dikembangkan sesuai kriteria sehingga mendapati tujuh kategori yang digunakan untuk wawancara.

Tabel 2. Pedoman Wawancara

\begin{tabular}{ll}
\hline No & Butir Pertanyaan \\
\hline 1 & $\begin{array}{l}\text { Bentuk-bentuk bullying yang dilakukan terhadap anak gagap oleh teman } \\
\text { sebaya. }\end{array}$ \\
\hline 2 & Dampak bullying terhadap korban \\
\hline 3 & Dampak bullying terhadap pelaku \\
\hline 4 & $\begin{array}{l}\text { Cara guru mengatasi (melerai) tindakan bullying terhadap anak gagap yang } \\
\text { sedang dilakukan oleh teman sebaya }\end{array}$ \\
\hline
\end{tabular}




\begin{tabular}{ll}
\hline 5 & $\begin{array}{l}\text { Cara guru mengetahui tentang mengatasi tindakan bullying terhadap anak } \\
\text { gagap yang dilakukan oleh teman sebaya. }\end{array}$ \\
\hline 6 & $\begin{array}{l}\text { Hambatan guru dalam mengatasi kasus bullying pada anak gagap oleh teman } \\
\text { sebaya. }\end{array}$ \\
\hline 7 & $\begin{array}{l}\text { Peran guru dalam upaya mengurangi adanya tindakan bullying terhadap anak } \\
\text { gagap oleh teman sebaya (menghilangkan budaya bullying). }\end{array}$ \\
\hline
\end{tabular}

\section{HASIL DAN PEMBAHASAN}

Hasil penelitian ini terdiri atas tujuh kategori, diantaranya yaitu bentuk-bentuk bullying yang dilakukan terhadap anak gagap oleh teman sebaya, dampak bullying terhadap korban, dampak bullying terhadap pelaku, cara guru mengatasi (melerai) tindakan bullying terhadap anak gagap yang sedang dilakukan oleh teman sebaya, cara guru mengetahui tentang mengatasi tindakan bullying terhadap anak gagap yang dilakukan oleh teman sebaya, hambatan guru dalam mengatasi kasus bullying pada anak gagap oleh teman sebaya, dan peran guru dalam upaya mengurangi adanya tindakan bullying terhadap anak gagap oleh teman sebaya (menghilangkan budaya bullying).

Tabel 3.

Bentuk-bentuk bullying yang dilakukan

terhadap anak gagap oleh teman sebaya.

\begin{tabular}{|c|c|c|}
\hline Kategori I & Kode & Kutipan \\
\hline \multirow[t]{2}{*}{$\begin{array}{l}\text { Bentuk bullying yang } \\
\text { dilakukan terhadap anak } \\
\text { gagap oleh teman sebaya. }\end{array}$} & $\begin{array}{lr}\text { Perilaku } & \text { verbal } \\
\text { langsung } & (\mathrm{N} 1), \\
(\mathrm{N} 2),(\mathrm{N} 3),(\mathrm{N} 4)\end{array}$ & $\begin{array}{l}\text { "Bentuk bullying-nya seperti } \\
\text { ejekan atau intimidasi terhadap } \\
\text { anak yang gagap ini." }\end{array}$ \\
\hline & $\begin{array}{lr}\text { Perilaku } & \text { non- } \\
\text { verbal, } & \text { tidak } \\
\text { langsung (N1), (N2) } & \end{array}$ & $\begin{array}{l}\text { "Dijauhi karena terlihat berbeda } \\
\text { dan tidak mengerti apa yang } \\
\text { dikatakan anak gagap tersebut." }\end{array}$ \\
\hline
\end{tabular}

Tabel 3 membahas kategori I mengenai bentuk-bentuk bullying yang dilakukan terhadap anak gagap oleh teman sebaya. Hasil yang sama diungkapkan oleh keempat narasumber bahwa perilaku verbal langsung merupakan bentuk bullying yang umumnya dilakukan terhadap anak gagap oleh teman sebaya di lingkup PAUD, seperti mengejek atau mengintimidasi mengenai cara berbicara pada anak gagap yang berbeda dari anakanak pada umumnya. Selain itu, narasumber satu (N1) dan narasumber dua (N2) menambahkan bahwa bentuk bullying pada anak gagap dapat berupa bullying dalam bentuk perilaku non-verbal tidak langsung. Artinya, anak gagap tersebut dijauhi atau tidak diajak bersosialisasi oleh teman-temannya dikarenakan mereka tidak mengerti apa yang dikatakan oleh anak gagap tersebut dan menganggap bahwa anak gagap adalah sosok yang 'berbeda'.

Anak mempunyai perspektif yang berbeda ketika melihat karakteristik temannya yang berbeda (Lee \& Park, 2009; Özokçu, 2019; Shenderovich, Thurston, \& Miller, 2014), dan tidak sedikit perbedaan dari karakteristik temannya menjadi bahan perbincangan antar teman dan ejekan (Isaacs, 2012; H. Kim, 2009). Bentuk-bentuk bullying tersebut sejajar dengan (Riauskina, Djuwita, \& Soesetio, 2005) yang mengelompokkan perilaku bullying menjadi lima kategori, diantaranya yaitu bullying dalam bentuk kontak verbal langsung dan perilaku non-verbal tidak langsung. 


\section{Psycho Idea, Volume 19 Nomer 01 Tahun 2021}

Tabel 4.

Dampak bullying terhadap korban

\begin{tabular}{lll}
\hline \multicolumn{1}{c}{ Kategori II } & \multicolumn{1}{c}{ Kode } & \multicolumn{1}{c}{ Kutipan } \\
\hline Dampak bullying & Muncul rasa & "Anak gagap ini kalau diejek kadang suka \\
terhadap korban & marah (N3), & $\begin{array}{l}\text { marah bahkan bisa melawan dengan main } \\
\text { (N4) }\end{array}$ \\
\cline { 2 - 3 } & fisik." \\
\hline
\end{tabular}

Tabel 4 membahas kategori II mengenai dampak bullying terhadap korban. Dampak bullying yang dialami korban dilihat dari jawaban keempat narasumber cukup beragam. Narasumber satu (N1) dan narasumber dua (N2) mengatakan bahwa korban bullying dapat mengalami gangguan psikis, seperti anak terkadang menjadi pemurung atau merasa rendah diri. Hal ini sejalan dengan (Smith, 2013) bahwa bullying dapat menyebabkan gangguan psikis terhadap korban. Selain itu, jawaban dari narasumber tiga (N3) dan narasumber empat (N4) menyatakan bahwa rasa marah dapat muncul pada anak gagap yang mendapat perilaku bullying dari temannya, bahkan korban bisa melawan dengan main fisik. Hal tersebut sesuai dengan pernyataan (Humphrey \& Crisp, 2008) bahwa seorang korban bullying dapat merasa kesal dan marah dengan kejadian tidak nyaman yang menimpa mereka.

Tabel 5.

Dampak bullying terhadap pelaku

\begin{tabular}{|c|c|c|}
\hline Kategori III & Kode & Kutipan \\
\hline \multirow[t]{3}{*}{$\begin{array}{l}\text { Dampak bullying } \\
\text { terhadap pelaku }\end{array}$} & $\begin{array}{l}\text { Bisa jadi kebiasaan } \\
\text { untuk mem-bully (N2), } \\
\text { (N4) }\end{array}$ & $\begin{array}{l}\text { "Karena keseringan mem-bully, } \\
\text { mungkin dia akan terbiasa jika } \\
\text { dibiarkan." }\end{array}$ \\
\hline & $\begin{array}{l}\text { Dapat teguran (N1), } \\
(\mathrm{N} 3),(\mathrm{N} 4)\end{array}$ & $\begin{array}{l}\text { "Pelaku juga dapat teguran dari guru } \\
\text { atau temannya." }\end{array}$ \\
\hline & Sosial (N1) & $\begin{array}{l}\text { "Pelaku dijauhi temannya karena } \\
\text { melakukan hal kurang sopan terhadap } \\
\text { korban." }\end{array}$ \\
\hline
\end{tabular}

Tabel 5 membahas kategori III mengenai dampak bullying terhadap pelaku. Narasumber dua (N2) dan narasumber empat (N4) menyatakan bahwa pelaku akan terbiasa untuk melakukan tindakan bullying jika dibiarkan, sebab pelaku akan menganggap bahwa tindakan bullying yang dilakukannya merupakan hal yang dapat dimaklumi. Selain itu, narasumber satu (N1), narasumber tiga (N3), dan narasumber empat (N4) mengungkapkan bahwa pelaku sudah pasti akan mendapatkan teguran dari guru. Narasumber satu (N1) menambahkan bahwa pelaku bisa mendapatkan sanksi sosial berupa dijauhi oleh teman-temannya karena perilaku tidak baik yang telah dilakukan terhadap korban.

Perilaku negatif anak akan mempengaruhi anak di tahapan perkembangan berikutnya (Devi, Fleer, \& Li, 2018; J. E. Kim, 2011; Pan, Trang, Love, \& Templin, 2019; Rochimah, Handini, \& Hapidin, 2020). Jika perilaku tersebut tidak mendapat treatment yang memadai akan berpotensi kecenderungan untuk menetap (Frabutt \& Waldron, 2013; 
Whittingham, Sanders, McKinlay, \& Boyd, 2013). Teguran dari orang dewasa di sekitarnya seperti guru dan orang tua, akan menjadikan anak mencoba untuk melakukan perlawanan dan tindakan yang lebih berani (Langley et al., 2011; Paul, Hart, Augustin, Clarke, \& Pike, 2020).

Tabel 6.

Cara guru mengatasi (melerai) tindakan bullying terhadap anak gagap yang sedang dilakukan oleh teman sebaya.

\section{Kategori IV}

Cara guru mengatasi (melerai) tindakan bullying terhadap anak gagap yang sedang dilakukan oleh teman sebaya

\section{Kode}

\begin{tabular}{|c|c|}
\hline $\begin{array}{l}\text { Memisah } \\
\text { kan (N3), (N4) }\end{array}$ & $\begin{array}{l}\text { "Saya samperin dulu mereka, } \\
\text { lalu saya pisahkan." }\end{array}$ \\
\hline $\begin{array}{l}\text { Tegur pelaku } \\
(\mathrm{N} 1),(\mathrm{N} 2)\end{array}$ & $\begin{array}{l}\text { "Kita sebagai guru tetap harus } \\
\text { menegur temannya atau pelaku." }\end{array}$ \\
\hline $\begin{array}{l}\text { Tenang } \\
\text { kan emosi marah } \\
\text { pada korban (N3) }\end{array}$ & $\begin{array}{l}\text { "Yang korban ini ditenangkan } \\
\text { dulu emosinya." }\end{array}$ \\
\hline $\begin{array}{l}\text { Refleksi diri pada } \\
\text { pelaku (N2) }\end{array}$ & $\begin{array}{l}\text { "Saya suruh mereka atau pelaku } \\
\text { untuk duduk, relax, pikirkan apa } \\
\text { yang telah dilakukan terhadapan } \\
\text { korban." }\end{array}$ \\
\hline $\begin{array}{l}\text { Cari tau faktor } \\
\text { penyebab (N2), } \\
(\mathrm{N} 3),(\mathrm{N} 4)\end{array}$ & $\begin{array}{l}\text { "Saya cari tau faktor mereka } \\
\text { berantem yang ternyata anak } \\
\text { gagap (korban) diejek oleh } \\
\text { temennya." }\end{array}$ \\
\hline $\begin{array}{l}\text { Beri nasihat (N1), } \\
(\mathrm{N} 2),(\mathrm{N} 3),(\mathrm{N} 4)\end{array}$ & $\begin{array}{l}\text { "Saya kasih nasihat dan } \\
\text { pengertian dengan bahasa yang } \\
\text { mudah dipahami oleh anak." }\end{array}$ \\
\hline $\begin{array}{l}\text { Berdamai (N2), } \\
(\mathrm{N} 3),(\mathrm{N} 4)\end{array}$ & $\begin{array}{l}\text { "Lalu saya ajak mereka untuk } \\
\text { saling minta maaf." }\end{array}$ \\
\hline $\begin{array}{l}\text { Memotivasi } \\
\text { korban (N1), } \\
(\mathrm{N} 2)\end{array}$ & $\begin{array}{l}\text { "Memberikan motivasi } \\
\text { semangat bahwa tiap orang pasti } \\
\text { punya kekurangan dan } \\
\text { kelebihan." }\end{array}$ \\
\hline $\begin{array}{l}\text { Perjanjian dan } \\
\text { punishment (N2) }\end{array}$ & $\begin{array}{l}\text { "Ada perjanjian, kalau korban } \\
\text { di-bully lagi dengan anak-anak } \\
\text { yang sama, maka akan ada } \\
\text { punishment." }\end{array}$ \\
\hline $\begin{array}{l}\text { Pertemuan orang } \\
\text { tua }(\mathrm{N} 2)\end{array}$ & $\begin{array}{l}\text { "Saya beritahu wali kelas } \\
\text { masing-masing untuk adakan } \\
\text { meeting dengan orang tua dan } \\
\text { berdiskusi bersama." }\end{array}$ \\
\hline
\end{tabular}

Tabel 7.

Cara guru mengetahui tentang mengatasi tindakan bullying terhadap anak gagap yang dilakukan oleh teman sebaya

Kategori V Kode Kutipan




\section{Psycho Idea, Volume 19 Nomer 01 Tahun 2021}

\begin{tabular}{|c|c|c|}
\hline \multirow{6}{*}{$\begin{array}{l}\text { Cara guru mengetahui tentang } \\
\text { mengatasi tindakan bullying } \\
\text { terhadap anak gagap yang } \\
\text { dilakukan teman sebaya }\end{array}$} & $\begin{array}{l}\text { Melalui } \\
\text { pengalaman guru } \\
\text { lain (N4) }\end{array}$ & $\begin{array}{l}\text { "Saya biasanya belajar dari } \\
\text { pengalaman guru lain dengan } \\
\text { bertanya." }\end{array}$ \\
\hline & $\begin{array}{l}\text { Melalui } \\
\text { pengetahuan } \\
\text { sendiri (N3) }\end{array}$ & $\begin{array}{l}\text { "Saya hanya melalui } \\
\text { pengalaman atau pengetahu } \\
\text { an sendiri." }\end{array}$ \\
\hline & $\begin{array}{l}\text { Melalui seminar } \\
\text { (N1) }\end{array}$ & $\begin{array}{l}\text { "Saya pernah ikut seminar } \\
\text { mengenai bullying pada anak } \\
\text { saat kuliah." }\end{array}$ \\
\hline & $\begin{array}{l}\text { Melalui buku } \\
\text { (N1) }\end{array}$ & $\begin{array}{l}\text { "Saya pernah membaca } \\
\text { beberapa buku mengenai } \\
\text { hambatan dan masalah anak } \\
\text { seperti ABK." }\end{array}$ \\
\hline & $\begin{array}{l}\text { Melalui orang tua } \\
\text { anak (N1) }\end{array}$ & $\begin{array}{l}\text { "Tahu dari orang tua anak } \\
\text { tentang cara mengatasi tindakan } \\
\text { yang dilakukan anaknya, karena } \\
\text { tiap anak beda-beda." }\end{array}$ \\
\hline & $\begin{array}{l}\text { Guru dan kuliah } \\
\text { mengenai anak } \\
\text { berkebutuhan } \\
\text { khusus (N2) }\end{array}$ & $\begin{array}{l}\text { "Saya kuliah di CAE yang } \\
\text { tentang anak berkebutuhan } \\
\text { khusus itu." }\end{array}$ \\
\hline
\end{tabular}

Tabel 6 membahas kategori IV mengenai cara guru PAUD mengatasi (melerai) tindakan bullying terhadap anak gagap yang sedang dilakukan oleh teman sebaya. Cara yang diterapkan antara narasumber satu dengan narasumber yang lain terbilang beragam dan dilakukan secara sistematis atau bertahap. Jawaban yang diungkapkan oleh narasumber tiga (N3) dan narasumber empat (N4) bisa dikatakan sebagai tahap pertama, yaitu menghampiri anak-anak ketika sedang terjadi tindakan bullying terhadap anak gagap dari teman sebaya, lalu memisahkannya. Tahap kedua yang diungkapkan oleh narasumber pertama (N1) dan narasumber kedua (N2) yaitu menegur pelaku. Menenangkan emosi marah pada korban yang diungkapkan oleh narasumber tiga (N3) termasuk ke dalam tahap ketiga. Lalu, narasumber kedua (N2) menyatakan bahwa guru perlu mengajak pelaku untuk duduk, relax, dan melakukan refleksi diri atau pikirkan apa yang telah dilakukannya terhadap korban. Tindakan tersebut dapat digolongkan ke dalam tahap keempat. Peran guru dalam menangani anak yang bermasalah dengan teman sebanyanya mempunyai peran yang sentral (Damianidou \& Phtiaka, 2018; H. Kim, 2009; Wilson et al., 2020).

Tahap selanjutnya, seperti yang dikatakan oleh narasumber dua (N2), narasumber tiga (N3), dan narasumber empat (N4), guru mencari tahu faktor penyebab korban dan pelaku saling bertengkar, yang dimana faktor penyebabnya adalah korban (anak gagap) diejek oleh temannya dan menyebabkan korban menjadi emosi. Kemudian, seluruh narasumber menyatakan bahwa guru perlu memberikan nasihat (pengertian), baik terhadap korban maupun pelaku, dengan bahasa yang mudah dipahami oleh anak. Narasumber dua (N2), narasumber tiga (N3), dan narasumber empat (N4) menjelaskan bahwa sebagai guru, ajak pelaku dan korban untuk saling minta maaf. Selanjutnya, narasumber satu (N1) dan narasumber dua (N2) mengatakan bahwa guru perlu memotivasi korban dengan memberikan semangat bahwa setiap orang pasti punya kekurangan dan kelebihan. Guru juga dapat membuat perjanjian dan punishment dengan 
korban dan pelaku. Artinya, hukuman akan diberikan jika kasus yang sama terulang. Guru juga dapat mengadakan pertemuan dan edukasi dengan orang tua anak untuk bersamasama saling berdiskusi tentang bagaimana mendidik anak secara optimal.

Penelitian yang dilakukan Mandiri (2017), cara guru mengatasi bullying di SD Muhammadiyah 6 Surakarta antara lain: 1) memanggil peserta didik yang terlibat kasus bullying, 2) meminta peserta didik menceritakan apa yang terjadi, 3) memberikan nasihat, 4) memberikan sanksi atau hukuman. Selain itu, penelitian Alfalah (2017) juga menyatakan cara mengatasi bullying di MI Negeri Trobayan Kalijambe Sragen sebagai berikut: 1) memanggil peserta didik yang terlibat ke dalam kasus bullying, 2) menelusuri permasalahan yang terjadi, 3) memberikan nasihat, 4) penanaman nilai agama, dan 4) memanggil orang tua jika diperlukan. Meski penelitian tersebut menyatakan peran guru di tingkat SD/MI, namun dilihat dari hasil wawancara menyatakan bahwa peran guru dalam mengatasi kasus bullying terhadap anak gagap oleh teman sebaya di jenjang PAUD tidak jauh berbeda dengan cara guru mengatasi kasus bullying di jenjang SD/MI. Guru mempunyai peran sentral dalam penanganan Anak Berkebutuhan Khusus (ABK) terkait bagaimana dalam menciptakan lingkungan yang kondusif (Harjani, 2020; Siron, 2018).

Berdasarkan Tabel 7 mengenai kategori $\mathrm{V}$, cara guru mengetahui tentang bagaimana mengatasi tindakan bullying terhadap anak gagap yang dilakukan oleh teman sebaya berasal dari sumber yang beragam, seperti melalui pengalaman guru lain, berdasarkan pengetahuan sendiri, melalui seminar mengenai bullying pada anak, melalui buku mengenai hambatan dan masalah anak seperti masalah pada anak berkebutuhan khusus (ABK), melalui orang tua anak tentang bagaimana orang tua mengatasi segala perilaku anak, dan terdapat narasumber lulusan CAE yang sudah memiliki pengalaman dan keahlian dalam menangani anak berkebutuhan khusus, termasuk mengatasi masalah bullying yang terjadi pada ABK atau bullying pada anak gagap.

Tabel 8.

Hambatan guru dalam mengatasi kasus bullying pada anak gagap oleh teman sebaya

\begin{tabular}{|c|c|c|}
\hline Kategori VI & Kode & Kutipan \\
\hline \multirow{5}{*}{$\begin{array}{l}\text { Hambatan guru dalam } \\
\text { mengatasi kasus bullying } \\
\text { pada anak gagap oleh } \\
\text { teman sebaya. }\end{array}$} & $\begin{array}{l}\text { Kewalahan } \\
\text { (N3) }\end{array}$ & $\begin{array}{l}\text { "Kadang kalau sudah sampai berantem, } \\
\text { saya kewalahan sampai-sampai minta } \\
\text { tolong guru lain untuk melerai." }\end{array}$ \\
\hline & $\begin{array}{l}\text { Menolak } \\
\text { berdamai (N4) }\end{array}$ & $\begin{array}{l}\text { "Kadang ada anak yang mem-bully dan } \\
\text { disuruh minta maaf, dia nggak mau." }\end{array}$ \\
\hline & $\begin{array}{ll}\text { Waktu } & \text { (N1), } \\
(\mathrm{N} 2), & \text { (N3), } \\
(\mathrm{N} 4) & \end{array}$ & $\begin{array}{l}\text { "Memberikan pengertian (nasihat) pada } \\
\text { anak tidak hanya dilakukan sekali, tapi } \\
\text { berkali-kali sehingga butuh waktu yang } \\
\text { tidak sebentar." }\end{array}$ \\
\hline & $\begin{array}{l}\text { Kesabaran } \\
\text { ekstra (N1), } \\
(\mathrm{N} 3)\end{array}$ & $\begin{array}{l}\text { "Butuh kesabaran ekstra dalam } \\
\text { memberikan nasihat (pengertian) pada } \\
\text { anak." }\end{array}$ \\
\hline & $\begin{array}{l}\text { Tidak ada } \\
\text { hambatan }(\mathrm{N} 2)\end{array}$ & $\begin{array}{l}\text { "Sejauh ini tidak pernah menemukan } \\
\text { hambatan karena lakukan dengan niat } \\
\text { tulus dan ikhlas semua selesai." }\end{array}$ \\
\hline
\end{tabular}




\section{Psycho Idea, Volume 19 Nomer 01 Tahun 2021}

Beberapa penelitian, seperti penelitian lain yang mengungkapkan bahwa hambatan guru dalam mengatasi kasus bullying yaitu sulitnya merubah watak siswa dan mudahnya siswa mengulangi perilaku bullying (Alfalah, 2017; Mandiri, 2017). Meski penelitian-penelitian tersebut menyatakan hambatan guru dalam mengatasi kasus bullying pada jenjang SD, ternyata hasil penelitian-penelitian tersebut tidak jauh berbeda dengan hambatan guru dalam menangani kasus bullying pada anak gagap oleh teman sebaya di jenjang PAUD yang telah dilakukan oleh peneliti. Tantangan guru dalam melibatkan teman sebaya untuk menerima kehadiran ABK di sekolah menjadi hal yang perlu ditindaklanjuti lebih jauh (Mulyono et al. 2015; Siron 2019; Siron 2018).

Tabel 8 membahas kategori VI mengenai hambatan yang dialami guru PAUD dalam mengatasi kasus bullying pada anak gagap oleh teman sebaya. Jawaban dari narasumber terkait hambatan tersebut kebanyakan dari waktu dan kesabaran. Guru perlu memiliki kesabaran ekstra dalam memberi nasihat (pengertian) pada anak ketika kasus bullying terjadi dan perlu melakukannya berkali-kali sebab kasus bullying tersebut bisa terulang sehingga tidak cukup jika hanya sekali diberikan nasihat. Hambatan lainnya diungkapkan oleh narasumber empat (N4) yakni terkadang pelaku tidak mau untuk diajak berdamai dan guru bisa sampai merasa kewalahan dalam menangani kasus bullying seperti yang dikatakan oleh narasumber tiga (N3).

Banyak hasil penelitian yang mengeksplorasi tantangan guru dalam mengatasi permasalahan dikelas yang perlu ditindak lanjuti (LaParo, Maynard, Thomason, \& ScottLittle, 2012; Monteiro, Kuok, Correia, Forlin, \& Teixeira, 2019), lebih lagi tantangan guru dalam melibatkan ABK dan teman sebayanya (Mónico et al., 2018; Siron, 2018; Somma, 2020; Sucuoğlu, Bakkaloğlu, Karasu, Demir, \& Akalin, 2013; Sucuoğlu, Bayrakli, Karasu, \& Demir, 2017).

Tabel 9.

Peran guru dalam upaya mengurangi adanya tindakan bullying terhadap anak gagap oleh teman sebaya (menghilangkan budaya bullying)

\begin{tabular}{|c|c|c|}
\hline Kategori VII & Kode & Kutipan \\
\hline \multirow{5}{*}{$\begin{array}{l}\text { Peran guru dalam upaya } \\
\text { mengurangi adanya tindakan } \\
\text { bullying terhadap anak gagap } \\
\text { oleh teman sebaya } \\
\text { (menghilangkan budaya } \\
\text { bullying) }\end{array}$} & $\begin{array}{l}\text { Memantau aktivitas } \\
\text { anak didik (N3) }\end{array}$ & $\begin{array}{l}\text { "Saya juga memantau } \\
\text { aktivitas anak agar } \\
\text { terkontrol dengan baik." }\end{array}$ \\
\hline & $\begin{array}{l}\text { Pengelolaan kelas } \\
\text { (N3) }\end{array}$ & $\begin{array}{l}\text { "Saya membuat kegiatan } \\
\text { belajar kelompok. Disitu } \\
\text { jadi muncul sifat berteman } \\
\text { karena saling bantu." }\end{array}$ \\
\hline & $\begin{array}{l}\text { Menjadi } \\
\text { 'pendengar' anak } \\
\text { (N3) }\end{array}$ & $\begin{array}{l}\text { "Saya mencoba 'terbuka' } \\
\text { untuk segala cerita yang } \\
\text { disampai } \\
\text { kan anak, termasuk cerita } \\
\text { tentang hal-hal yang } \\
\text { ganggu mereka.” }\end{array}$ \\
\hline & $\begin{array}{l}\text { Menjadi teladan } \\
\text { yang baik (N4) }\end{array}$ & $\begin{array}{l}\text { "Lebih ke gurunya sih ya, } \\
\text { untuk menjadi teladan yang } \\
\text { baik." }\end{array}$ \\
\hline & $\begin{array}{l}\text { Pemberi nasihat } \\
\text { atau pengertian }\end{array}$ & $\begin{array}{l}\text { "Guru memberi nasihat } \\
\text { agar anak-anak saling } \\
\text { sayang terhadap sesama." }\end{array}$ \\
\hline
\end{tabular}


(N1), (N2), (N3),

(N4)

\begin{tabular}{ll}
\hline $\begin{array}{l}\text { Pemberian reward } \\
\text { (N1) }\end{array}$ & $\begin{array}{l}\text { "Hari ini tidak ada yan } \\
\text { menangis atau bertengkar, } \\
\text { saya beri reward." }\end{array}$ \\
\hline $\begin{array}{l}\text { Konsultasi psikolog } \\
\text { keluarga (N2) }\end{array}$ & $\begin{array}{l}\text { "Saya adakan yang } \\
\text { namanya konsultasi } \\
\text { psikolog keluarga." }\end{array}$ \\
\hline Mengadakan & "Sering-sering adakan \\
edukasi tentang & edukasi atau seminar \\
anak berkebutu & tentang anak berkebutuhan \\
han khusus (N2) & khusus, baik itu gagap, \\
& gangguan emosional, dan \\
& segala macam untuk guru, \\
& anak-anak, dan lain-lain."
\end{tabular}

Tabel 9 membahas kategori VII mengenai peran guru dalam upaya mengurangi adanya tindakan bullying terhadap anak gagap oleh teman sebaya (menghilangkan budaya bullying). Keempat narasumber menyatakan bahwa pemberian nasihat (pengertian) pada anak didik agar saling menyayangi terhadap sesama tanpa membeda-bedakan antara satu dengan yang lain merupakan salah satu peran guru PAUD dalam upaya mengurangi adanya tindakan bullying pada anak gagap dari teman sebaya. Narasumber satu (N1) menambahkan bahwa pemberian reward kepada anak didik dapat dilakukan oleh guru jika pada hari itu tidak ada anak-anak yang menangis atau melakukan pertengkaran. Reward dapat berupa pemberian bintang di tangan atau di stiker penilaian anak. Reward menjadi penting bagi anak untuk dapat terkontrol perilaku positifnya (Matondang, 2017; A. K. Sari et al., 2020; Talwar, Yachison, \& Leduc, 2016).

Begitu pula dengan narasumber dua (N2) yang menambahkan bahwa konsultasi psikolog keluarga perlu dilakukan untuk menjalin komunikasi dan kerjasama antara guru dan orang tua anak didik guna mengurangi terjadinya kasus bullying pada anak. Edukasi (seminar) tentang anak berkebutuhan khusus, baik untuk guru, anak-anak, dan lain-lain juga dapat dilakukan. Narasumber tiga (N3) menambahkan peran guru yang lain, seperti memantau aktivitas anak agar terkontrol dengan baik, melakukan pengelolaan kelas dengan membentuk kelompok belajar, dan menjadi 'pendengar' segala cerita yang disampaikan oleh anak. Selain itu, narasumber empat (N4) mengungkapkan bahwa guru perlu menjadi teladan yang baik di sekolah sebab anak usia dini cenderung meniru apa yang dilakukan oleh orang-orang disekitarnya. Keteladan guru menjadi role model anak dalam berperilaku keseharian (Carew, Deluca, Groce, \& Kett, 2019; Mónico et al., 2018; Sucuoğlu et al., 2013).

Beberapa penelitian tentang peran guru dalam upaya mengurangi adanya tindakan bullying (Alfalah, 2017; Arumsari \& Setyawan, 2019; Ismail, 2019; Mandiri, 2017). Meski penelitian-penelitian tersebut rata-rata bukan menyatakan peran guru PAUD, namun hasil penelitian-penelitian tersebut tidak jauh berbeda dengan hasil wawancara peneliti terhadap keempat narasumber mengenai peran guru di jenjang PAUD dalam upaya mengurangi adanya tindakan bullying terhadap anak gagap oleh teman sebaya (menghilangkan budaya bullying). 


\section{Psycho Idea, Volume 19 Nomer 01 Tahun 2021}

\section{KESIMPULAN}

Bullying pada anak gagap di jenjang PAUD dilakukan dalam bentuk perilaku verbal langsung dan perilaku non-verbal tidak langsung. Perilaku bullying dapat memberikan dampak negatif terhadap korban dan juga pelaku bullying itu sendiri. Mengatasi perilaku bullying tidak bisa hanya dalam satu kali saja, tetapi dibutuhkan usaha yang terus menerus dan bertahap. Berdasarkan hasil penelitian, cara guru PAUD dalam mengatasi kasus bullying pada anak gagap oleh teman sebaya yaitu: 1) memisahkan pelaku dan korban, 2) menegur pelaku, 3) menenangkan korban dan pelaku, 4) mencari tahu faktor dan penyebab, 5) memberikan pengertian dan nasihat, 6) mengajak pelaku dan korban untuk berdamai, 7) memotivasi korban, 8) membuat perjanjian dan hukuman jika mengulangi hal yang sama terhadap pelaku atau orang lain, 9) mengadakan pertemuan orang tua.

Hambatan guru PAUD dalam mengatasi perilaku bullying pada anak gagap oleh teman sebaya kemungkinan besar pasti ada. Hambatan tersebut diantaranya yaitu, membutuhkan waktu dan kesabaran yang ekstra, tidak ada keinginan untuk berdamai antara korban dan pelaku, serta guru PAUD bisa sampai kewalahan jika sampai terjadi pertengkaran antara korban dan pelaku. Peran guru PAUD dalam mengurangi adanya kasus bullying pada anak gagap oleh teman sebaya antara lain, memantau aktivitas peserta didik, melakukan pengelolaan kelas, menjadi pendengar yang baik untuk anak, menjadi teladan yang baik, memberikan pengertian dan nasihat, memberikan reward, konsultasi dengan psikolog dan orang tua, serta mengadakan edukasi (seminar) mengenai anak berkebutuhan khusus.

Penelitian ini masih terbatas pada 4 partisipan sehingga kedalaman perlu digali pada penelitian selanjutnya dengan memperdalam jumlah informan. Begitu juga dengan kajian topik bullying pada anak gagap, perlu dikembangkan model tratment guru pada korban maupun pelaku bullying agar perilaku bullying bisa diminimalisasi.

\section{DAFTAR PUSTAKA}

Alfalah, Z. A. A. (2017). Peran Guru dalam Mengatasi Bullying di MI negeri Trobayan Kalijambe Sragen. Universitas Muhammadiyah Surakarta.

Alfatihaturrohmah, Mayangsari, D., \& Karim, M. B. (2018). Kemampuan Berbicara Anak Usia 5-6 Tahun di TK X Kamal. Jurnal PG-PAUD Trunojoyo: Jurnal Pendidikan Dan Pembelajaran Anak Usia Dini, 5(2), 101-109. http://doi.org/10.21107/pgpaudtrunojoyo.v5i2.4885

Arumsari, A. D., \& Setyawan, D. (2019). Peran Guru dalam Pencegahan Bullying di PAUD. Motoric, 2(1), 34-43. http://doi.org/10.31090/paudmotoric.v2i1.739

Carew, M. T., Deluca, M., Groce, N., \& Kett, M. (2019). The impact of an inclusive education intervention on teacher preparedness to educate children with disabilities within the Lakes Region of Kenya. International Journal of Inclusive Education, 23(3), 229-244. http://doi.org/10.1080/13603116.2018.1430181

Choirudin, M. (2019). Peran Guru Dalam Menanggulangi Perilaku Bullying Pada Siswa Madrasah Ibtidaiyah Maarif Maesan Lendah Kulon Progo Yogyakarta Tahun Pelajaran 2018. UIN Sunan Kalijaga.

Cook, S., \& Howell, P. (2014). Bullying in Children and Teenagers Who Stutter and the Relation to Self-Esteem, Social Acceptance, and Anxiety. Perspectives on Fluency and Fluency Disorders, 24(2), 46-57. http://doi.org/10.1044/ffd24.2.46

Damianidou, E., \& Phtiaka, H. (2018). Implementing inclusion in disabling settings: the role of 
teachers' attitudes and practices. International Journal of Inclusive Education, 22(10), 1078-1092. http://doi.org/10.1080/13603116.2017.1415381

Devi, A., Fleer, M., \& Li, L. (2018). "We set up a small world": preschool teachers' involvement in children's imaginative play. International Journal of Early Years Education, 26(3), 295311. http://doi.org/10.1080/09669760.2018.1452720

Frabutt, J. M., \& Waldron, R. (2013). Reaching the Youngest Hearts and Minds: Interviews with Diocesan Leaders Regarding Catholic Early Childhood Education. Catholic Education: A Journal of Inquiry and Practice, 17(1), 5-40. Retrieved from http://search.proquest.com/docview/1509085639?accountid=13042

Fradelos, E. (2015). Children With Stuttering at School. Journal of Human and Social Science Research, 5(1), 01-07.

Garvis, S., Pendergast, D., \& Kanasa, H. (2013). Early Childhood Education and Care Policy in Australia: An Insight into Parent Perceptions Posted Online, 7(3), 103-119.

Goryl, O., Neilsen-Hewett, C., \& Sweller, N. (2013). Teacher education, teaching experience and bullying policies : Links with early childhood teachers' perceptions and attitudes to bullying. Australasian Journal of Early Childhood, 38(2), 32-40.

Harjani, H. J. (2020). Interaksi Sosial Anak Nonreguler di SLB Zinnia Jakarta. JECE (Journal of Early Childhood Education), 2(1), 49-61.

Humphrey, G., \& Crisp, B. R. (2008). Bullying Affects Us Too: Parental Responses to Bullying at Kindergarten. Australian Journal of Early Childhood, 33(1), 45-49.

Indah, R. N. (2017). Gangguan Berbahasa: Kajian Pengantar. Uin-Maliki Press (Vol. 15). Malang: UIN Maliki Press.

Isaacs, J. (2012). The Social Genome Project. School at a Disadvantage: The School Readiness of Poor Children. Centre on Children and Families at Brookings, (December 2011), 1-22.

Ismail, T. (2019). Pentingnya Peran Guru Kelas Dalam Mengatasi Perilaku Bullying Siswa Di Sekolah. Prosiding Seminar Nasional PGSD, 1(1), 283-289.

Kim, H. (2009). Roles of teachers and peers in conflicts between Korean kindergarteners, 3(2), 23-52.

Kim, J. E. (2011). Holistic Development of the Young Child through an Integrated Curriculum : Rudolf Steiner' s Anthroposophical Research, 5(1), 161-170.

King-Sears, M. E., \& Strogilos, V. (2020). An exploratory study of self-efficacy, school belongingness, and co-teaching perspectives from middle school students and teachers in a mathematics co-taught classroom. International Journal of Inclusive Education, 24(2), 162180. http://doi.org/10.1080/13603116.2018.1453553

Langley, K., Martin, J., Agha, S. S., Davies, C., Stergiakouli, E., Holmans, P., ... Thapar, A. (2011). Clinical and cognitive characteristics of children with attention-deficit hyperactivity disorder, with and without copy number variants. British Journal of Psychiatry, 199(5), 398-403. http://doi.org/10.1192/bjp.bp.111.092130

LaParo, K. M., Maynard, C., Thomason, A., \& Scott-Little, C. (2012). Developing Teachers' Classroom Interactions: A Description of a Video Review Process for Early Childhood Education Students. Journal of Early Childhood Teacher Education, 33(3), 224-238. http://doi.org/10.1080/10901027.2012.705809

Lathifah, A. N. (2019). Peran Guru Dalam Menangani Perilaku Tindakan Bullying Siswa Kelas V Di MIN Baki Sukoharjo Tahun Ajaran 2018/2019. Institut Agama Islam Negeri Surakarta.

Lee, J. H., \& Park, J. E. (2009). Differences of children' s verbal interaction in peer collaboration according to age, gender, and pairing conditions, 3(2), 105-121.

Mandiri, J. A. (2017). Peran Guru Dalam Mengatasi Perilaku Bullying Pada Siswa Kelas Atas Di SD Muhammadiyah 6 Surakarta. Universitas Muhammadiyah Surakarta.

Matondang, E. S. (2017). Perilaku Prososial (Prosocial Behavior) Anak Usia Dini Dan Pengelolaan Kelas Melalui Pengelompokan Usia Rangkap (Multiage Grouping). EduHumaniora | Jurnal Pendidikan Dasar Kampus Cibiru, 8(1), 34. http://doi.org/10.17509/eh.v8i1.5120 


\section{Psycho Idea, Volume 19 Nomer 01 Tahun 2021}

Mónico, P., Mensah, A. K., Grünke, M., Garcia, T., Fernández, E., \& Rodríguez, C. (2018). Teacher knowledge and attitudes towards inclusion: a cross-cultural study in Ghana, Germany and Spain. International Journal of Inclusive Education, O(0), 1-17. http://doi.org/10.1080/13603116.2018.1471526

Monteiro, E., Kuok, A. C. H., Correia, A. M., Forlin, C., \& Teixeira, V. (2019). Perceived efficacy of teachers in Macao and their alacrity to engage with inclusive education. International Journal of Inclusive Education, 23(1), 93-108. http://doi.org/10.1080/13603116.2018.1514762

Mulyono, R., Suhyanto, O., Siron, Y., \& Rochimah, N. (2015). Pengaruh Intensi, Motivasi, dan Pemahaman Guru terhadap Implementasi Pendidikan Inklusif. Jurnal Pendidikan Usia Dini, 11(2), 293-307. http://doi.org/https://doi.org/10.21009/JPUD.112.08

Nusantara, A. (2008). Bullying: mengatasi kekerasan di sekolah dan lingkungan. Jakarta: Grasindo.

Özokçu, O. (2019). Investigation of Peer Relationships of Children with and without Special Needs in the Preschool Period. International Journal of Early Childhood Special Education, 10(2018), 92-105. http://doi.org/10.20489/intjecse.506875

Pan, Q., Trang, K. T., Love, H. R., \& Templin, J. (2019). School Readiness Profiles and Growth in Academic Achievement. Frontiers in Education, 4(November). http://doi.org/10.3389/feduc.2019.00127

Paul, S. A. S., Hart, P., Augustin, L., Clarke, P. J., \& Pike, M. (2020). Parents' perspectives on home-based character education activities. Journal of Family Studies, 0(0), 1-23. http://doi.org/10.1080/13229400.2020.1806097

Putri, D. A. W. M. (2017). Media Anti Bullying: Pembimbingan Anak Usia Dini Pada Taman Kanak-Kanak Di Kota Singaraja. Jurnal Widya Laksana, 5(1), 29. http://doi.org/10.23887/jwl.v5i1.9101

Rahmawati, A., Tairas, M. M. W., \& Nawangsari, N. A. F. (2018). Children's School Readiness: Teachers' and Parents' Perceptions. International Journal of Pedagogy and Teacher Education, 2(1), 9. http://doi.org/10.20961/ijpte.v2i1.14876

Riauskina, I. I., Djuwita, R., \& Soesetio, S. R. (2005). Gencet-gencetan" di mata siswa/siswi kelas 1 SMA: Naskah kognitif tentang arti, skenario, dan dampak" gencet-gencetan". Jurnal Psikologi Sosial, 12(1), 1-13.

Robinson, G., \& Maines, B. (2008). Bullying: A Complete Guide to The Support Group Method. London: Sage Publication Ltd.

Rochimah, N., Handini, M. C., \& Hapidin. (2020). Effect of family factor and children' s school readiness in integrated waste treatment places: path analysis. JECE (Journal of Early Childhood Education), 2(2), 97-112. http://doi.org/http://dx.doi.org/10.15408/jece.v2i2.17055

Rozie, F., Haryani, W., \& Safitri, D. (2019). Peran Guru Dalam Penanganan Perilaku Anak Hiperaktif Di TK Negeri 1 Samarinda. JECE (Journal of Early Childhood Education), 1(2), 53-59. http://doi.org/http://dx.doi.org/10.15408/jece.v1i2.12874

Sari, A. K., Neviyarni, Karneli, Y., \& Netrawati. (2020). Fostering prosocial behaviours of early childhood through group guidance with a client centered therapy approach. JECE (Journal of Early Childhood Education), 2(2), 170-182. http://doi.org/http://dx.doi.org/10.15408/jece.v2i2.18141

Sari, H., \& Gökdağ, H. (2017). An analysis of difficulties of children with stuttering enrolled in Turkish primary inclusive classes who encounter in academic and social activities: From their perspectives. Journal of Education and Practice, 8(2), 31-43. Retrieved from www.asha.org

Shenderovich, Y., Thurston, A., \& Miller, S. (2014). Cross-age tutoring in kindergarten and elementary school settings: A systematic review and meta-analysis. International Journal of Educational Research (Vol. 76). http://doi.org/10.1016/j.ijer.2015.03.007

Siron, Y. (2018). Implementing Inclusive Education: What are Elementary Teacher Obstacles? Case Study in East Jakarta , Indonesia. In International Conference on Diversity and 
Disability Inclusion in Muslim Societies (ICDDIMS 2017) Implementing (Vol. 153, pp. 177180). Jakarta: Advances in Social Science, Education and Humanities Research.

Siron, Y. (2019). Kendala Guru PAUD Mengembangkan Sentra Membaca dan Menulis (Studi Kasus di Jakarta Timur). Cakrawala Dini: Jurnal Pendidikan Anak Usia Dini, 10(2), 2-10.

Siron, Y. (2020). PAUD Inklusif: Pengaruh Efikasi Diri dan Tingkat Literasi Guru Terhadap kemampuan Merancang Individualized Education Program. Al-Athfal: Jurnal Pendidikan Anak, 6(1), 1-14. http://doi.org/http://dx.doi.org./10.14421/al-athfal.2020.61-01

Siron, Y., Khotimah, K., \& Sholeha, S. S. A. (2020). Parenting sukses: menghadapi bully teman bagi anak gagap. Jurnal AUDI Jurnal Ilmiah Kajian Ilmu Anak Dan Media Informasi PAUD, 5(2), 64-74.

Siswati, \& Widayanti, C. G. (2009). Fenomena Bullying di Sekolah Dasar di Semarang: Sebuah Studi Deskriptif. Jurnal Psikologi Undip, 5(2).

Small, P., Neilsen-hewett, C., \& Sweller, N. (2013). Individual and Contextual Factors Shaping Teachers 'Attitudes and Responses to Bullying among Young Children: Is Education Important ?, 7(3), 69-101.

Smith, P. K. (2013). School bullying. Sociologia, Problemas E Praticas, 71, 81-98. http://doi.org/10.7458/SPP2012702332

Somma, M. (2020). From segregation to inclusion: special educators' experiences of change. International Journal of Inclusive Education, 24(4), 381-394. http://doi.org/10.1080/13603116.2018.1464070

Souto-Manning, M. (2013). Teaching young children from immigrant and diverse families. YC Young Children, 68(4), 72-80.

Sucuoğlu, B., Bakkaloğlu, H., Karasu, F. I., Demir, Ş., \& Akalin, S. (2013). Inclusive preschool teachers: Their attitudes and knowledge about inclusion. International Journal of Early Childhood Special Education, 5(2), 107-128. http://doi.org/10.20489/intjecse.107929

Sucuoğlu, N. B., Bayrakli, H., Karasu, F. I., \& Demir, Ş. (2017). The preschool classroom management and inclusion in Turkey. International Journal of Early Childhood Special Education, 9(2), 66-80. http://doi.org/10.20489/intjecse.107991

Talwar, V., Yachison, S., \& Leduc, K. (2016). Promoting honesty: The influence of stories on children's lie-telling behaviours and moral understanding. Infant and Child Development, 25(6), 484-501.

Tanod, M. J. (2018). Upaya Guru Bimbingan dan Konseling dalam Meningkatkan Sikap Sosial Siswa Melalui Pendekatan Client Centered Therapy pada Siswa SMP. KONSELI: Jurnal Bimbingan Dan Konseling, 5(2), 85-96.

Whittingham, K., Sanders, M., McKinlay, L., \& Boyd, R. N. (2013). Stepping Stones Triple P and Acceptance and Commitment Therapy for Parents of Children with Cerebral Palsy: Trial Protocol. Brain Impairment, 14(2), 270-280. http://doi.org/10.1017/BrImp.2013.19

Wilson, C., Marks Woolfson, L., \& Durkin, K. (2020). School environment and mastery experience as predictors of teachers' self-efficacy beliefs towards inclusive teaching. International Journal of Inclusive Education, 24(2), 218-234. http://doi.org/10.1080/13603116.2018.1455901

Yoshikazu, K., Toshiro, U., Motohiro, S., Masahiko, T., Yumi, Y., Daisuke, M., \& Takashi, N. (2019a). Experiences of Teasing and Bullying in Children Who Stutter. International Archives of Communication Disorder, 2(2). http://doi.org/10.23937/2643-4148/1710013

Yoshikazu, K., Toshiro, U., Motohiro, S., Masahiko, T., Yumi, Y., Daisuke, M., \& Takashi, N. (2019b). Experiences of Teasing and Bullying in Children Who Stutter. International Archives of Communication Disorder, 2(2), 1-4. http://doi.org/10.23937/2643$4148 / 1710013$ 